\title{
Processing of Extruded BPSCCO Superconductor-PMMA Composite for Sintering and Texture Development
}

\author{
U. S. HAREESH, C. Sunil KUMAR, T. V. MANI, G. M. Anil KUMAR, \\ A. D. DAMODARAN and K. G. K. WARRIER ${ }^{\dagger}$ \\ Regional Research Laboratory, Council of Scientific \& Industrial Research, Trivandrum 695 019, India \\ 押し出し成形された BPSCCO 超伝導体-PMMA 複合体の焼結 \\ 及び組織成長のためのプロセッシング \\ U. S. Hareesh, C. Sunil Kumar, T. V. Mani, G. M. Anil Kumar, \\ A. D. Damodaran and K. G. K. Warrier ${ }^{\dagger}$ \\ Regional Research Laboratory, Council of Scientific \& Industrial Research, Trivandrum 695 019, India
}

[Received May 25, 1994; Accepted April 1, 1995]

\begin{abstract}
Bi-based superconducting shapes were fabricated by extrusion of ceramic-polymer mixture involving a solgel derived superconductor and in situ polymerized polymethylmethacrylate as binder. The powder was intimately mixed with methylmethacrylate monomer and polymerized in the presence of other organic additives such as butylbenzyl phthalate, phosphate ester and benzoyl peroxide. The viscous mass was then extruded to wires $3 \mathrm{~mm}$ in diameter and $25 \mathrm{~mm}$ in length. They were heat-treated at controlled rates for binder burn out and sintering at $840^{\circ} \mathrm{C}$ for $20 \mathrm{~h}$. Zone melting refining was carried out on the sintered samples in a three-zone furnace at a controlled speed of $30 \mathrm{~mm}$ per hour for introducing texture. The surface morphology of starting powder and microstructure of fractured surface of sintered and textured wires are presented and compared.
\end{abstract}

Key-words : Bi-based superconductor, Extrusion, Zone melting refining

\section{Introduction}

The preparation of lead-doped bismuth based superconductors (BPSCCO) has been reported based on many methods, starting from mixture of oxides, ${ }^{1)}$ chemical methods involving sol-gel,2),3) microwave synthesis, ${ }^{4)}$ freeze drying ${ }^{5)}$ and thermal decomposition of salt. ${ }^{6), 7)}$ Metal acetate derived superconducting films by sol-gel method were reported recently. $\left.{ }^{8}\right)$ Processes are now available for obtaining 2223 rich BPSCCO powder having small grain sizes prepared under short heat treatment schedules for further processing to useful shapes such as wires, tapes and interconnects, in addition to films. Enhancement of texture in the sintered BPSCCO has also been attempted by several heat treatment techniques ${ }^{9), 10)}$ in bulk samples. Compacted shapes of suspension spun BSCCO filaments were subjected to zone melting by Goto and Aoki ${ }^{11)}$ in order to get high current densi-

${ }^{\dagger}$ Address for correspondence ties. Further, viscous compacting ${ }^{12)}$ and zone melting refining ${ }^{13)}$ techniques on BPSCCO superconductors resulted in considerable improvement in $a-b$ plane orientation of grains. On the other hand, nonaqueous extrusion using polypropylene carbonate binder ${ }^{14)}$ was used for fabricating different shapes. Generally such binders should have a definite burn out pattern leaving no residues and should be amenable for easy polymerization. Further, it should be possible to achieve critical powder volume concentration (CPVC) in addition to interaction with the surface of the oxide particles to ensure homogeneity of mixture. Polymethyl methacrylate (PMMA) has recently been identified suitable for preparation of polymer-ceramic mixtures. ${ }^{15)}$ This polymer is characterized by sharp binder burn out through degradation to methyl methacrylate monomer at around $320^{\circ} \mathrm{C}$, and hence leaves least carbon residues. However, in ceramic polymer mixtures, the temperature of decomposition of the polymer is shifted to higher range due to the oxide particle ester interactions ${ }^{16), 17)}$ depending on the metal-oxygen bonding in the oxides. In the present investigation, BPSCCO powders prepared through acrylate-gel route ${ }^{18)}$ has been extruded to wires involving PMMA as the binder phase. These samples have been sintered after subjecting to binder burn out schedules followed by texturing further using zone melting refining process.

\section{Experimental}

BPSCCO powder $\left(\mathrm{Bi}_{1.8} \mathrm{~Pb}_{0.2} \mathrm{Sr}_{2} \mathrm{Ca}_{2} \mathrm{Cu}_{3} \mathrm{O}_{10+x}\right)$ prepared by acrylate gel decomposition route was finely ground and mixed with methyl methacrylate in toluene medium and phosphate ester as dispersant. The composition of a typical mixture is given in Table 1. This mixture was ball milled for $10 \mathrm{~h}$ to obtain a uniform distribution of the powder. Butyl benzyl phthalate and benzoyl peroxide were then added and the resultant slurry was refluxed in nitrogen atmosphere for $6 \mathrm{~h}$. Methyl methacrylate polymerizes to PMMA as evidenced by the increased viscosity. 
Table 1. Typical Composition of the Mixture

$\begin{array}{lc}\text { Component } & 60 \\ \text { BPSCCO Powder } & 20 \\ \text { Toluene } & 15 \\ \text { Methyl methacrylate } & 4.5 \\ \text { Butyl benzyl phthalate (S-160) } & 0.12 \\ \text { Benzoyl peroxide } & 0.3 \\ \text { Phosphate ester } & \\ & \end{array}$

This viscous mass was extruded in a stainless steel extruder having nozzle size ranging from $0.2 \mathrm{~mm}$ to $3 \mathrm{~mm}$ diameter. The wires were made into different shapes as shown in Fig. 4 and then dried under vacuum followed by heat treatment at controlled rates of $25^{\circ} \mathrm{C}$ per hour upto $500^{\circ} \mathrm{C}$ for binder burn out and sintered at $840^{\circ} \mathrm{C}$ for $20 \mathrm{~h}$.

\section{Results and discussion}

The BPSCCO powder was characterized by XRD and was found to contain $>95 \% 2223$ phase. Methyl methacrylate was polymerized in presence of BPSCCO powder in finely dispersed form to ensure maximum interaction between the polymer and the superconductor. The maximum mixing and dispersion of fine BPSCCO particle with the monomer was obtained by the ball milling and could ensure uniform distribution of fine powder in the polymerized network. Polymerization was done at controlled rates to obtain a viscous mass suitable for extrusion. The polymer cross-linked network was embedded with fine BPSCCO particulates. The PMMA content in this mixture was $15 \%$ by weight (14\% by volume) which was the minimum required to keep the fluidity adequate for extrusion to required shapes (Fig. 4). Viscosity measurements were not done. The drying was done under partial vacuum (3-10 $\mathrm{mm} \mathrm{Hg}$ ) in the beginning $(5 \mathrm{~h})$ and later at $60^{\circ} \mathrm{C}$ in an electric oven. The DTA of the PMMA-ceramic mixture (Fig. 1) showed endothermic decomposition at $287^{\circ} \mathrm{C}, 333^{\circ} \mathrm{C}$ and $380^{\circ} \mathrm{C}$, respectively. The endothermic peak at $287^{\circ} \mathrm{C}$ may be due to the monomer degradation which remained in the system because under the present conditions, the polymerization was not allowed to complete, due to the increasing viscosity. The peak at $332^{\circ} \mathrm{C}$ is characteristic of PMMA degradation to monomer and the endotherm at $380^{\circ} \mathrm{C}$ would be the degradation of the polymer network linked up with the oxide superconductor. In fact the increase in the degradation temperature of the ceramic-polymer mixture at high temperatures is already reported. ${ }^{19)}$ The rate of heating for the binder burn out was adjusted to be $25^{\circ} \mathrm{C} / \mathrm{h}$ at which condition, the ceramic shape is maintained for sintering and densification. Sintering was done on extruded

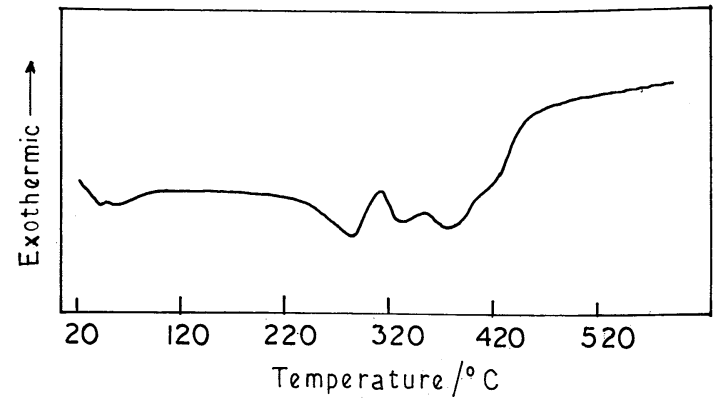

Fig. 1. DTA of ceramic-polymer mixture.



Fig. 2. XRD pattern of (a) sintered sample and (b) textured sample.

samples of $60 \mathrm{~mm}$ long and $2 \mathrm{~mm}$ diameter at $840^{\circ} \mathrm{C}$ over a period of $20 \mathrm{~h}$ when densification $>85 \%$ was obtained. These samples were further subjected to zone melting refining where the orientation is effected in partially melt matrix under the thermal drag. The XRD pattern taken on samples just after sintering and zone melting are presented in Fig. 2 which shows the considerable extent of texturing achieved as a result of the zone melting operation. The extent of texturing can further be observed by comparing micrographs of the starting BPSCCO powder, fractographs of as extruded, sintered and zone melted samples (Fig. 3). The BPSCCO powder particles range in sizes $1-2 \mu \mathrm{m}$ (Fig. 3a). The extruded compact is rather densely packed and partly oriented in the direction of extrusion, more predominantly at the peripheral areas (Fig. 3b). The grains have further grown to large flaky ones in sintering and then tend to orient in the $a-b$-plane on the post sintering operation (Figs. 3c, 3d). The earlier studies more or less deal with samples having fibres or discs of small thickness, compared to extruded samples of 1-2 mm diameter and lengths near $60 \mathrm{~mm}$ in the present investigation. A few typical shapes for possible applications as high $T_{\mathrm{c}}$ microwave antenna prepared by the present technique are presented in Fig. 4. Thus, by starting from a high $T_{\mathrm{c}}$ powder, it has been possible to use sol-gel derived fine powders to extrude reasonably large size wires using PMMA as binder and heat-treated and then further subjected to zone 


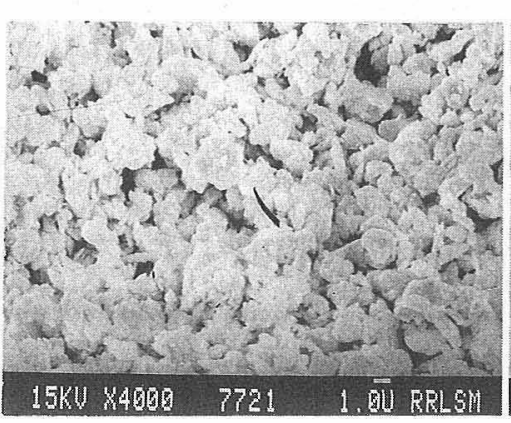

(a)

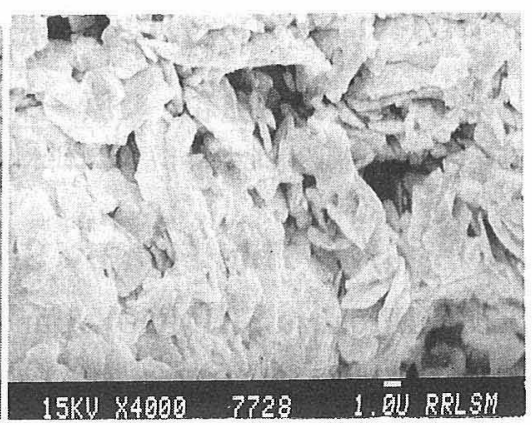

(b)

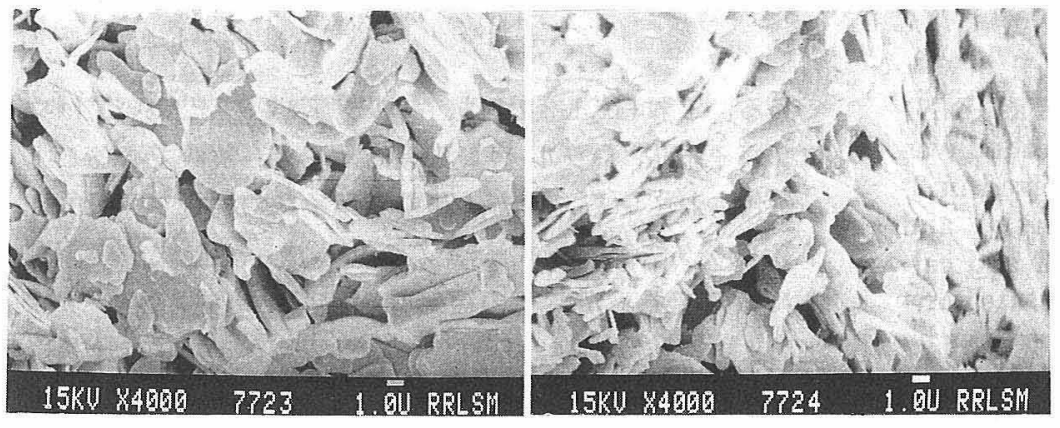

(c)

Fig. 3

(d)

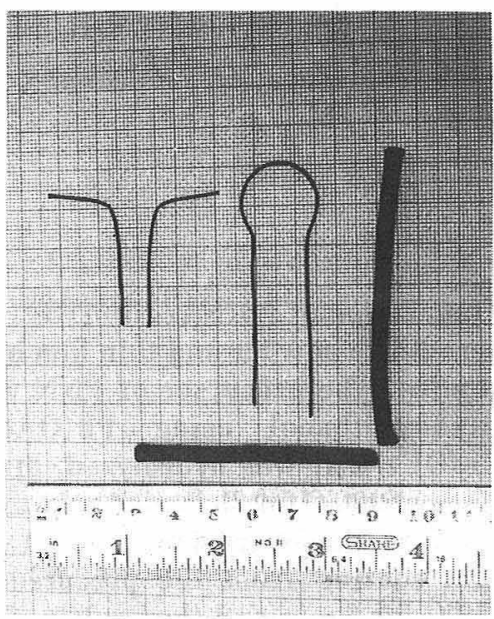

Fig. 4

Fig. 3. SEM micrographs of (a) powder morphology and fractographs of (b) green wire (c) sintered wire and (d) textured wire. Fig. 4. Extruded shapes for microwave applications.

refining to result in reasonably textured superconductors.

\section{Conclusion}

BPSCCO powder made through acrylate gel decomposition route has been extruded to rods which have been subjected to binder burn out, sintering and texturing. The grain size increased on texturing to $10 \mu \mathrm{m}$ and density was greater than $90 \%$. Any long lengths can be subjected to moving furnace zone melting and refining to obtain textured grains.

\section{References}

1) M. M. Garland, Appl. Phys. Lett., 52, 1913-14 (1988).

2) K. Tanaka, A. Nosue and K. Kamiya, J. Mater. Sci., 25, 3551-56 (1990).

3) S. Hirano, T. Hayashi and H. Tomonaga, Jpn. J. Appl. Phys., 29, L40-42 (1990).

4) H. K. Varma, K. G. K. Warrier, V. Ajithkumar, T. V. Mani, S. G. K. Pillai and A. D. Damodaran, Jpn. J. Appl. Phys., 31, L543-46 (1992).

5) H. Medelius and D. J. Rowcliffe, Mater. Sci. Eng., A109 (12), 289-92 (1989).

6) R. Srinivasan, M. Sam, R. J. De Angelis, J. O. Deasy, J. W. Brill and C. E. Hamrin, Jr., J. Mater. Sci. Lett., 8, 383-86 (1989).
7) U. Endo, S. Koyama and T. Kawai, Jpn. J. Appl. Phys., Part 2, 27, L1476-79 (1988).

8) H. R. Zhuang, H. Kozuka, T. Yoko and S. Sakka, Jpn. J. Appl. Phys., 29, L1107 (1990).

9) K. H. Sandhage, G. N. Riley, Jr. and W. L. Carter, J. Metals, 43, 21-25 (1991).

10) M. Shoyama, H. Nasu and K. Kamiya, Jpn. J. Appl. Phys., 30, 950 (1991).

11) T. Goto and T. Aoki, Physica C, 170, 427 (1990).

12) T. V. Mani, A. D. Damodaran and K. G. K. Warrier, Brit. Ceram. Trans., 92, 246-50 (1993).

13) T. V. Mani, A. D. Damodaran and K. G. K. Warrier, J. Mater. Sci., 29, 6453-57 (1994).

14) H. K. Varma, P. Mukundan, K. G. K. Warrier, A. D. Damodaran and U. Balachandran, J. Am. Ceram. Soc., 73, 3100-02 (1990).

15) G. S. Grader and L. Zuri, J. Am. Ceram. Soc., 76, 1809-14 (1993).

16) F. M. Fowkes and M. A. Mostafa, IEC Prod. Res. Dev., 17, 3-7 (1978)

17) H. Pines and W. O. Haag, J. Am. Chem. Soc., 82, 2471-83 (1960).

18) T. V. Mani, H. K. Varma, K. G. K. Warrier and A. D. Damodaran, Brit. Ceram. Trans. J., 91, 120-23 (1992).

19) Y. N. Sun, M. D. Sacks and J. W. Williams, "Ceramic Transactions, Vol. 1", Ed. by G. L. Messing, The Am. Ceram. Soc., Westerville, OH (1988) pp. 538-45. 